Final Published Version is: Miao, C., Humphrey, R. H., \& Qian, S. (2017). A meta-analysis of emotional intelligence effects on job satisfaction mediated by job resources, and a test of moderators. Personality and Individual Differences. 116, 281-288.

http://dx.doi.org/10.1016/j.paid.2017.04.031

\title{
A Meta-Analysis of Emotional Intelligence Effects on Job Satisfaction Mediated by Job Resources, and a Test of Moderators
}

\begin{abstract}
This paper examines whether job resources act as a mediator in the emotional intelligence (EI) — job satisfaction relationship, and examines possible moderators, including gender, age, tenure, and job level. We conducted a meta-analysis to explore these relationships. The metaanalysis demonstrated that: First, EI is positively related to job resources $(k=15, N=4,151$; overall EI: $\hat{\rho}=.27$; ability EI: $\hat{\rho}=.24$; self-report EI: $\hat{\rho}=.27$; mixed EI: $\hat{\rho}=.28)$. Second, job resources mediate the relationship between EI and job satisfaction. Third, the relationship between EI and job satisfaction does not differ across gender, age, and tenure, meaning that regardless of whether an employee is male or female, young or old, or having short or long tenure, they equally benefit from EI. The moderator effect of job level is only significant for self-report EI - job satisfaction and this relationship is stronger in non-managerial jobs than in managerial jobs. Yet, the moderator effect of job level is not significant for ability EI-job satisfaction and mixed EI—job satisfaction meta-analytic distributions. Theoretical and practical implications are discussed.
\end{abstract}

Keywords: Emotional intelligence; job resources; job satisfaction 


\section{A Meta-Analysis of Emotional Intelligence Effects on Job Satisfaction Mediated by Job Resources, and a Test of Moderators INTRODUCTION}

Salovey and Mayer (1990) are widely credited with developing the first modern definition of emotional intelligence (EI), and they conceptualized emotional intelligence as the ability to perceive emotions and to regulate emotions, both with regard to oneself and to others. Goleman popularized EI in his internationally best-selling books (Goleman, 1995; Goleman, Boyatzis, \& McKee, 2002), and scholars began to argue that EI is essential to organizational success (Cherniss, 2001). Ashkanasy and Daus (2005) reviewed the emerging research on EI and classified the measures of emotional intelligence into three types; these are stream 1 ability EI, stream 2 self-report EI, and stream 3 mixed EI measures. For simplicity's sake, we refer to them as ability EI, self-report EI, and mixed EI. Ability measures emphasize that EI is a type of intelligence, and they measure EI the way cognitive intelligence is usually measured, with objective right and wrong answers on tests. For example, Mayer and his coauthors (Mayer, Salovey, Caruso, \& Sitarenios, 2003, p. 99) developed the MSCEIT V2.0, "a 141-item scale designed to measure the following four branches (specific skills) of EI: (a) perceiving emotions, (b) using emotions to facilitate thought, (c) understanding emotions, and (d) managing emotions." In contrast, many scholars in the self-report category regard emotional intelligence as a type of trait, and they measure it with self-report items consistent with how traits are often measured. For example, Petrides and his colleagues defined EI as "a constellation of behavioral dispositions and self-perceptions concerning one's ability to recognize, process, and utilize emotion-laden information." (Petrides, Frederickson, \& Furnham, 2004, p. 278). Finally, mixed EI measures incorporate a broader range of emotion-related skills and competencies than do stream 2 self- 
report measures, and they conceptualize EI in broader terms. Some popular measures in this category include the Bar-On Emotional Quotient Inventory (EQ-i) (Bar-On, 2000, 2002) and the Emotional and Social Competency Inventory (Boyatzis, Brizz, \& Godwin, 2011).

Petrides and his colleagues believe that trait EI encompasses the "emotion-related facets of personality" (Petrides, Pita, \& Kokkinaki, 2007, p. 287). Support for this position is provided by a comprehensive meta-analysis that investigated the associations between ability and trait EI with the "general factor of personality" (van der Linden, et al., 2017). The authors conclude that trait EI may be tantamount to the social effectiveness dimension of personality and to the general factor of personality. This research suggests that EI may aid employees in gaining resources, such as support from coworkers, supervisors, and subordinates, because of their greater social effectiveness.

The concept of EI has garnered enormous amounts of attention from researchers and scholars (e.g., Andrei, Siegling, Aloe, Baldaro, \& Petrides, 2016; Ashkanasy \& Daus, 2005; Boyatzis \& Goleman, 2002; Boyatzis, Brizz, \& Godwin, 2011; Goleman, 1995; Mayer \& Salovey, 1997; Miao, Humphrey, \& Qian, 2016a, 2016b; O’Boyle, Humphrey, Pollack, Hawver, \& Story, 2011; Petrides \& Furnham, 2000, 2001, 2003, 2006; Petrides, 2009a, 2009b; Petrides et al., 2016; Salovey \& Mayer, 1990; Walter, Cole, \& Humphrey, 2011). Meta-analyses have confirmed that EI has important outcomes. For example, two meta-analyses have found that EI improves physical, mental, and psychosomatic health (Martins, Ramalho, \& Morin, 2010; Schutte, Malouff, Thorsteinsson, Bhullar, \& Rooke, 2007). To address the concerns regarding the uniqueness of EI, O'Boyle et al.'s (2011) meta-analysis demonstrated that EI contributed significant incremental validity and relative importance in predicting job performance in the presence of cognitive ability and Big Five personality traits. Recent meta-analyses (e.g., Andrei 
et al., 2016; Miao et al., 2016a, 2016b) further confirmed EI's uniqueness in predicting additional criteria beyond job performance after common covariates that are considered to overlap with EI were controlled.

Miao et al. (2016b) performed a meta-analysis on EI and work attitudes and found that EI not only predicts job satisfaction, organizational commitment, and turnover intentions, but also demonstrates incremental variance and relative importance above and beyond cognitive ability and Big Five personality traits. There are a few areas that still require further exploration. First, three mediators were identified in Miao et al.'s (2016b) meta-analysis, which are: state positive affect, state negative affect, and job performance. We argue that another prominent type of mediator should be tested, which is job resources. Since emotionally savvy individuals can harness their EI to facilitate social interactions with other organizational members and to garner social support from their peers and supervisors (Byron, 2007; Kafetsios \& Zampetakis, 2008), this may lead to positive perceptions of job resources that will engender job satisfaction. This potential theoretical mechanism (EI $\rightarrow$ job resources $\rightarrow$ job satisfaction) has been implied but not examined in prior studies. Hence, the investigation of this mediator could make a significant theoretical contribution to EI literature. We will integrate a job demand-resources (JD-R) model (Bakker \& Demerouti, 2007; Demerouti, Bakker, Nachreiner, \& Schaufeli, 2001) with the EI literature and explore how EI relates to job resources, which in turn leads to job satisfaction. Hence, the first purpose of this meta-analysis is to test whether job resources mediates the relationship between EI and job satisfaction.

Second, Miao et al.'s (2016b) meta-analysis only analyzed one moderator, namely the emotional labor demand of jobs, whereas many other potential moderators related to subjects' demographics and job type have not yet been investigated. These moderators deserve 
examination because the use of EI has been theorized by some to be influenced by gender, age, tenure, and job level; as such, these potential moderators may condition the relationship between EI and job satisfaction. Thus, the second purpose of this meta-analysis is to explore how the aforementioned moderators condition the relationship between EI and job satisfaction.

\section{THEORY AND HYPOTHESES}

\section{Job Demand-Resources Model and the Mediating Role of Job Resources}

The JD-R model (Bakker, Demerouti, de Boer, \& Schaufeli, 2003; Bakker \& Demerouti, 2007; Demerouti et al., 2001) assumes that whereas every occupation has its own specific risk factors related to job stresses, these factors can be classified into two general categories - job demands and job resources - that constitute an overarching model that may be applicable to various occupational settings, regardless of the particular resources and demands involved (Crawford, LePine, \& Rich, 2010; Nahrgang, Morgeson, \& Hofmann, 2011). Job demands refer to "those physical, psychological, social, or organizational aspects of the job that require sustained physical and/or psychological (cognitive and emotional) effort or skills and are therefore associated with certain physiological and/or psychological costs", whereas job resources are defined as "those physical, psychological, social, or organizational aspects of the job that are either/or: functional in achieving work goals; reduce job demands and the associated physiological and psychological costs; stimulate personal growth, learning, and development" (Bakker \& Demerouti, 2007, p. 312). According to conservation of resources (COR) theory (Hobfoll, 2001), humans are motivated to protect, maintain, and accumulate resources. Job demands cause resources to be depleted as individuals respond to demands, thus gradually draining one's energy and, over time, leading to burnout (Crawford et al., 2010). Conversely, job resources trigger a motivational process that helps individuals accomplish their goals, stimulate 
their personal growth/development, and reduce job demands, therefore leading to positive outcomes such as engagement and satisfaction (Crawford et al., 2010; Nahrgang et al., 2011).

We propose that EI should be positively associated with job resources, and job resources should partially mediate the relationship between EI and job satisfaction. A positive social relationship with supervisors and co-workers is one key type of job resources (Bakker \& Demerouti, 2007). EI is essential to facilitate social interaction and to establish and maintain social relationships (Goleman, 1995; Lopes et al., 2004; Schutte, Malouff, Bobik, Coston, Greeson, \& Jedlicka, 2001). Emotionally savvy individuals are sensitive to not only their own but also to others' feelings and emotions (Johnson \& Spector, 2007); accordingly, they can harness their emotion perception and regulation abilities in order to foster better social relationships with their coworkers and supervisors, which allows them to acquire job resources from their coworkers and supervisors through productive social exchanges (Wong \& Law, 2002). For instance, emotionally intelligent persons can infer their coworkers' and/or supervisors' intentions from their emotional cues and thus communicate more effectively with them (Lopes et al., 2004). Interactions based on positive social exchanges allow emotionally intelligent people to accumulate job resources over time (e.g., coworkers' and/or supervisors' support, feedback, and job autonomy, etc.) because their exchange partners (e.g., coworkers and/or supervisors) may feel obligated to reciprocate all the benefits associated with their pleasurable social exchanges. Job satisfaction is derived from not only one's feeling towards a job but also one's rational/cognitive appraisal of a job (Judge \& Kammeyer-Mueller, 2012). Job satisfaction has a cognitive component, suggesting that one's job satisfaction hinges on one's beliefs or thoughts about the job (e.g., job characteristics, coworker relationship, supervisor relationship, etc.) and this belief/thought is developed from learning, reading, seeing, and hearing about the attitude 
object (Judge \& Kammeyer-Mueller, 2012). Job resources should positively impact one's cognitive assessment of the job and enhance one's job satisfaction because they offer various physical, psychological, social, or organizational benefits to employees. Meta-analytic findings support a positive relationship between job resources and job satisfaction (Nahrgang et al., 2011). Taken together, EI helps one to acquire job resources, and the acquisition of job resources in turn positively influences one's job satisfaction, suggesting the mediating role of job resources in the relationship between EI and job satisfaction. Thus, the following hypotheses can be claimed:

Hypothesis 1: EI is positively related to job resources.

Hypothesis 2: Job resources mediate the relationship between EI and job satisfaction.

\section{Moderators}

Gender. Men and women may differ in their ability to use EI. Some research findings have demonstrated that females are better at using emotions, reading others' feelings from facial expressions, and perceiving non-verbal emotional cues to help them respond with more appropriate affective responses than males (Byron, 2007; Koveshnikov, Wechtler, \& Dejoux, 2014; Salguero, Extremera, \& Fernández-Berrocal, 2012). Females have a greater capacity than males to express emotions and to manage their emotions in order to help them deal with stress and emotional tasks (Jung \& Yoon, 2014). As such, females may benefit more from using EI to enhance job satisfaction than their male counterparts (Johnson \& Spector, 2007). However, other studies have found no support for the presumed female advantage in emotional competencies (Taylor \& Hood, 2011). Thus, it is important to see if gender differences affect the relationship between EI and job satisfaction. Therefore, we derive the following hypothesis: 
Hypothesis 3: Gender moderates the relationship between EI and job satisfaction such that the relationship is stronger in female-dominated studies.

Age. Some research findings have indicated that EI develops and improves with age, as a result of maturation, learning, and training (Extremera, Fernández-Berrocal, \& Salovey, 2006; Mayer, Caruso, \& Salovey, 1999; Mayer \& Salovey, 1997). Older individuals are better at using EI to regulate their emotions to deal with negative feelings and to maintain and experience more positive feelings, and thus have higher job satisfaction (El Badawy \& Magdy, 2015). Older employees are more versed at understanding others' emotions and body language, and this helps them act in ways that facilitate social relationships with others in the workplace (El Badawy \& Magdy, 2015). As such, we develop the following hypothesis:

Hypothesis 4: Age moderates the relationship between EI and job satisfaction such that the relationship is stronger for older employees.

Tenure. We suggest that there may be two primary reasons why employees with long organizational tenure should be better at using EI to increase job satisfaction. First, employees with long organizational tenure are more socialized into their organizations relative to new employees; as such, employees with long tenure may benefit more from EI because it makes it easier and more beneficial for them to foster social relationships in order to enhance their job satisfaction (Denton \& Kleiman, 2001; Kraemer \& Gouthier, 2014). Second, EI develops as a consequence of learning and training (Mayer \& Salovey, 1997; Mayer et al., 1999). Compared to employees with short tenure, those with long tenure should have gained more experience in how to utilize EI to regulate their feelings and foster social relationships with others in order to enhance job satisfaction. On the other hand, some research has found that EI is most useful during the early forming stages of groups because it helps members quickly understand each 
other (Jordan, Ashkanasy, Härtel, \& Hooper, 2002). This implies that EI may be especially useful for employees with low tenure. To investigate these competing possibilities, we propose the following hypothesis:

Hypothesis 5: Tenure moderates the relationship between EI and job satisfaction such that the relationship is stronger when tenure is long.

Job level. The relationship between EI and job satisfaction may also vary as a function of hierarchical position level. Employees in high-level job positions (e.g., the ones in managerial roles) have more resources at their disposal (Stahl \& Caligiuri, 2005). As such, the relationship between EI and job satisfaction might be weakened for managers because they have many other alternative resources that they can deploy to enhance their job satisfaction. As a result, they may rely less on EI to enhance their job satisfaction. For instance, in light of their freedom and authority to use resources, employees in managerial positions can use problem-focused coping strategies to directly deal with job demands as a way to enhance their job satisfaction, rather than utilize emotion-focused coping strategies (e.g., use of EI) (Nahrgang et al., 2011; Stahl \& Caligiuri, 2005). In contrast, employees working in low-level jobs (e.g., the ones in nonmanagerial positions) are limited in their control and possession of resources; as such, due to a lack of alternatives, they might depend more heavily on EI to handle job demands in order to maintain their job satisfaction (Nahrgang et al., 2011), thus strengthening the relationship between EI and job satisfaction. To test these speculations, we provide the following hypothesis:

Hypothesis 6: Job level moderates the relationship between EI and job satisfaction such that the relationship is stronger for employees in non-managerial positions.

\section{METHOD}

\section{Literature Search}


We adhered to the following procedures in order to capture relevant articles. First, we did a computerized search of several electronic databases, including ABI/INFORM, EBSCO Host, Google, Google Scholar, JSTOR, ProQuest Dissertations and Theses, PsycNET, ScienceDirect, and Social Science Citation Index. Second, we also searched journals in the fields of management and psychology, including Academy of Management Journal, Administrative Science Quarterly, Journal of Applied Psychology, Journal of Management, Journal of Management Studies, Journal of Occupational and Organizational Psychology, Journal of Organizational Behavior, Journal of Personality and Social Psychology, Journal of Vocational Behavior, Organization Science, Personnel Psychology, and Personality and Individual Differences. Third, we searched pertinent management and psychology conferences, including the Academy of Management Annual Meeting, the Southern Management Association Annual Meeting, and the Society for Industrial and Organizational Psychology Annual Conference. We also reached out to EI scholars to request for unpublished papers, correlation matrices, and raw data.

\section{Inclusion Criteria}

We used the following criteria to filter the articles we identified. First, since metaanalytic reviews are quantitative, we excluded all qualitative studies identified during the search

process. Second, primary studies must provide at least one correlation coefficient between EI and job resources, so in the absence of correlation coefficients, we utilized Lipsey and Wilson's (2001) and Peterson and Brown's (2005) methods to convert relevant statistics into effect sizes. Third, we excluded the studies based on non-employee samples (e.g., student samples). Only studies that sampled real employees were included in the meta-analysis. Fourth, some studies only used proxy measures of EI, such as self-monitoring scales. Although proxy measures of EI, 
such as self-monitoring measure, are related to EI, they do not capture all the important elements of EI. Therefore, including these studies that used proxy measures of EI may contaminate our meta-analytic results. In line with O'Boyle et al.'s (2011) practice, we only included studies based on the scales that were explicitly designed to measure EI. After the aforementioned inclusion criteria were implemented, our search finally resulted in 15 eligible samples for the EI-job resources relationship. All references for the studies included in the EI-job resources meta-analytic distribution are noted in the reference section. Since the part regarding moderator analyses for the EI-job satisfaction relationship is a follow-up study for Miao et al. (2016b), we not only took their codes but also coded for additional moderators, as hypothesized in the present study, based on the studies they identified.

\section{Coding Procedures}

We coded three types of EI (i.e., ability EI, self-report EI, and mixed EI) based on Ashkanasy and Daus (2005). We followed the coding scheme developed by Crawford et al. (2010) to guide our coding of job resources, because their meta-analysis is the most comprehensive quantitative review of the JD-R model so far and their definition of job resources closely aligns with the theme of our paper. In line with Crawford et al.'s meta-analysis, we clustered different types of job resources (e.g., coworker support, supervisor support, and organizational support) together to form a broad category of job resources. As for gender moderator, we coded the percentage of male respondents for each study and used a median split to allocate them into male-dominated and female-dominated groups (Bae, Qian, Miao, \& Fiet, 2014). We coded average tenure (in years) of subjects for each study. According to the U.S. Bureau of Labor Statistics, there is no agreed-upon standard for short versus long tenure, due to distinctions across occupations. As such, we categorized them into long versus short tenure 
groups by applying a median split. We coded the average age (in years) of subjects for each study and used the benchmark of 40 years old to classify studies into young group and middle- or old-age group. A study was coded as managerial when the subjects in a study performed jobs that required them to control, supervise/oversee, and/or be in charge of others. Otherwise, it was coded as non-managerial.

\section{Analytic Methods}

We performed meta-analyses based on Hunter and Schmidt (2004). In line with prior meta-analytic reviews (Garrett, Miao, Qian, \& Bae, 2017; Miao, Qian, \& Ma, 2017), we followed Hunter and Schmidt's (1990) approach (i.e., z-test) to test moderators. We performed meta-analytic structural equation modeling (MASEM) (Viswesvaran \& Ones, 1995) to analyze the mediating role of job resources.

\section{RESULTS}

\section{Main and Moderator Effects}

Table 1 displays the results for both main and moderator effects. We found that the relationship between overall EI and job resources is positive and significant $(\hat{\rho}=.27)$ because the $95 \%$ confidence interval ranges from .24 to .31 , which does not include zero. Similarly, each individual EI stream also positively and significantly relates to job resources $(\hat{\rho}=.24$ for ability EI, $\hat{\rho}=.27$ for self-report EI, and $\hat{\rho}=.28$ for mixed EI). Hence, Hypothesis 1 is supported.

We performed moderator analyses for each individual EI stream and the results for moderator effects have been demonstrated in the last column of Table 1. With regard to ability EI—job satisfaction meta-analytic distribution, our results indicated that ability EI-job satisfaction relationships do not differ across male-dominated $(\hat{\rho}=.07)$ and female-dominated subgroups $(\hat{\rho}=.06)$, which translates into a .01 between-group effect size difference that is not 
significant according to z-test. We found the same patterns of non-significant results in selfreport EI—job satisfaction and mixed EI—job satisfaction distributions as well. Hence, Hypothesis 3 is not supported. We repeated the same procedures to analyze the other moderators. In sum, job level is a significant moderator only for the self-report EI-job satisfaction relationship. Age is a non-significant moderator for the relationships between all three types of EI and job satisfaction. Tenure is a non-significant moderator for the relationship between selfreport EI and job satisfaction. Taken altogether, Hypotheses 4 and 5 are not supported, and Hypothesis 6 is supported only for self-report EI-job satisfaction meta-analytic distribution.

\section{Insert Table 1 about here}

MASEM. We performed MASEM to test the mediating role of job resources. Considering the moderate multicollinearity between mixed EI and ability EI, and the high multicollinearity between mixed EI and self-report EI, we separated mixed EI from ability EI and self-report EI when conducting MASEM because the existence of multicollinearity would lead to issues of bouncing betas and lower statistical power, plus it would increase standard errors and yield uninterpretable results (Schwab, 2005). We did not separate ability EI and selfreport EI when performing MASEM, due to small multicollinearity between these two types of EI.

We conducted MASEM to assess and compare a set of alternative models (see Table 2). Regarding Test 1 in Table 2, we evaluated how job resources mediate the relationships between ability EI and self-report EI and job satisfaction. We compared all other models to the partial mediation model (a), which has direct paths from both ability EI and self-report EI to job satisfaction. We found that any deletion of paths from the partial mediation model (a) would worsen model fit according to $\chi^{2}$ difference test (see the results for $\chi^{2}$ difference test in the last 
column in Table 2). As such, the partial mediation model (a) was chosen in Test 1 in Table 2. We repeated the same procedure for Test 2 in Table 2, where job resources mediate the relationship between mixed EI and job satisfaction. The chosen model in Test 2 was the partial mediation model denoted with bold characters in Table 2.

\section{Insert Table 2 about here}

Figure 1 displays both path models and mediation results, along with all standardized path coefficients for the chosen models. Figure 1 (a) corresponds to Model 1 under Test 1 in Table 2, and Figure 1 (b) corresponds to Model 1 under Test 2 in Table 2. We conducted three types of mediation tests - Sobel test, Aroian test, and Goodman test.

With respect to Figure 1 (a), the indirect effect from ability EI to job satisfaction via job resources is $.13(p<.001$ [Sobel test: 5.32; Aroian test $=5.31$; Goodman test $=5.33$ ] $)$ and the indirect effect from self-report EI to job satisfaction via job resources is .15 $(p<.001$ [Sobel test: 6.09; Aroian test $=6.08$; Goodman test $=6.10])$. With regard to Figure $1(b)$, the indirect effect from mixed EI to job satisfaction via job resources is .16 $(p<.001$ [Sobel test: 13.56; Aroian test $=13.55$; Goodman test $=13.56])$. Since all of the indirect effects are statistically significant, Hypothesis 2 is supported.

\section{Insert Figure 1 about here}

\section{DISCUSSION}

If emotion is properly used and managed, the use of emotion can lead to a state of wellbeing (Humphrey, 2013; Humphrey, Ashforth, \& Diefendorff, 2015). Individuals high on EI are versed at using and managing their emotions to achieve better workplace outcomes. Miao et al. (2016b) demonstrated that employees may utilize their EI to enhance their job satisfaction because EI helps one to experience more positive feelings, to reduce negative feelings, and to 
accomplish performance goals. The present meta-analytic review adds to their finding by showing that employees may also use their EI to acquire job resources from their work in order to improve their job satisfaction.

\section{Theoretical Implications}

Our study explored the theoretical mechanism through which EI influences job satisfaction. Building on the JD-R model, we found that the relationship between EI and job satisfaction is mediated by job resources, suggesting that EI enhances job resources as a way to influence job satisfaction. Our study extended the JD-R model and COR theory to EI literature by showing how individuals can make use of EI to manage their emotions in order to acquire job resources and thereby influence their job satisfaction. However, we still need to clarify that our meta-analysis, because it is mostly based on cross-sectional studies, cannot capture the dynamics/fluctuations of job resources, whereas both the JD-R model and COR are dynamic theories (Bakker \& Bal, 2010; Halbesleben, Neveu, Paustian-Underdahl, \& Westman, 2014; Kammeyer-Mueller, Simon, \& Judge, 2016). We call for future studies to apply experience sampling methods and perform multilevel analyses to test how between-individual traits (e.g., emotional intelligence) influence within-individual variations in job resources, and how multiple job resources interact to affect workplace outcomes.

We also examined how a set of demographic characteristics influenced the EI-job satisfaction relationship. We found that the relationship between EI and job satisfaction is not influenced by gender, age, or tenure. As for gender, our findings demonstrated that males and females do not differ in their EI and that they equally benefit from using EI to enhance their job satisfaction. We also did not find any evidence that older individuals are more proficient at using EI to boost their job satisfaction. Interestingly, we did find that self-report EI-job satisfaction is 
stronger in non-managerial jobs than in managerial jobs. It supports our argument that individuals having managerial positions may rely less on EI to enhance their job satisfaction because they have many other alternative resources to make them feel satisfied, whereas individuals in lower level jobs have fewer resources at their disposal and may rely more on EI to maintain and boost job satisfaction (Nahrgang et al., 2011; Stahl \& Caligiuri, 2005). However, the mixed results for this with regard to the other two measures of EI suggest that more research on this is needed before a firm conclusion can be drawn.

\section{Limitations and Future Directions}

First, studies based on cross-sectional designs dominate our meta-analytic review; therefore, we cannot exclude the possibility of reverse causality (or reciprocal causation). This limitation has particular relevance to our mediation analyses because the term mediation implies a causal direction (Colquitt et al., 2007). We encourage future studies to perform advanced analyses (e.g., latent growth modeling) and to collect longitudinal data so that robust causal inference can be drawn.

Second, although all three streams of EI are statistically significantly related to job resources, the magnitude of effect sizes is still small. None of the uncorrected effect sizes meets the benchmark of moderate correlation (.30) (Cohen, 1988). Even after statistical artifacts were corrected, effect sizes still fail to reach the benchmark of medium correlation. Correction for statistical artifacts only results in a small increase, which ranges from .03 to .05 in effect sizes because the measures of both EI and job resources generally demonstrate satisfactory reliability across studies and effect sizes were not severely attenuated by measurement errors. The other source of statistical artifacts that we did not correct is range restriction. Range restriction may attenuate effect sizes reported in this study because the standard deviation of EI may be restricted 
in that only those high on EI were hired. Correction for range restriction requires the unrestricted standard deviation to be entered into the formula. Unfortunately, the unrestricted standard deviation is often unavailable or is challenging to determine (Roth et al., in press). We encourage future EI scholars to report any unrestricted standard deviation of EI so that meta-analysts can do a more accurate quantitative synthesis of literature.

Third, based on what we have identified, a fruitful avenue would be to integrate all variables examined in the present study in order to theorize and test moderated mediation models or mediated moderation models. The analysis of these models would have to be based on raw data, whereas meta-analytic techniques are based on correlation coefficients and not on raw data. Future studies may collect primary data to investigate moderated mediation models or mediated moderation models.

\section{Practical Implications}

This study has several important practical implications. First, it indicates that organizations should recruit and select emotionally intelligent employees in order to have a satisfied workforce. Second, it suggests that individuals should seek to develop their own emotional competencies because doing so could help them gain job resources at work and boost their job satisfaction as well. Third, organizations should provide job resources and other forms of support to their employees in order to maintain a satisfied work force. Supervisory support is a key job resource (Bakker \& Demerouti, 2007), and studies have found that leaders high on EI have employees with higher job satisfaction (Miao et al., 2016a; Walter, Humphrey, \& Cole, 2012). Thus, training leaders as well as followers in emotional intelligence and emotional competencies should improve job satisfaction as well. 


\section{REFERENCES}

References marked with an asterisk (*) refer to the studies included in the meta-analysis.

Andrei, F., Siegling, A. B., Aloe, A. M., Baldaro, B., \& Petrides, K. V. (2016). The incremental validity of the Trait Emotional Intelligence Questionnaire (TEIQue): A systematic review and meta-analysis. Journal of Personality Assessment, 98, 261-276.

Ashkanasy, N. M., \& Daus, C. S. (2005). Rumors of the death of emotional intelligence in organizational behavior are vastly exaggerated. Journal of Organizational Behavior, 26, $441-452$.

Bae, T. J., Qian, S., Miao, C., \& Fiet, J. O. (2014). The relationship between entrepreneurship education and entrepreneurial intentions: A meta-analytic review. Entrepreneurship Theory and Practice, 38, 217-254.

*Baik, D. W., \& Yom, Y. H. (2012). Effects of social support and emotional intelligence in the relationship between emotional labor and burnout among clinical nurses. Journal of Korean Academy of Nursing Administration, 18, 271-280.

Bakker, A. B., \& Bal, M. P. (2010). Weekly work engagement and performance: A study among starting teachers. Journal of Occupational and Organizational Psychology, 83, 189-206.

Bakker, A. B., Demerouti, E., de Boer, E., \& Schaufeli, W. B. (2003). Job demands and job resources as predictors of absence duration and frequency. Journal of Vocational Behavior, 62, 341-356.

Bakker, A. B., \& Demerouti, E. (2007). The job demands-resources model: State of the art. Journal of Managerial Psychology, 22, 309-328.

Bar-On, R. (2000). Emotions and social intelligence: Insights from the emotional quotient inventory. In R. Bar-On \& J. D. A. Parker (Eds.), The handbook of emotional 
intelligence: Theory, development, assessment, and application at home, school, and in the workplace (pp.363-388). San Francisco: Jossey-Bass.

Bar-On, R. (2002). Bar-On EQ-i technical manual. Toronto: Multi-Health Systems.

*Benson, J. D. (2009). The relationship between emotional intelligence and managers' use of specific directive and supportive behaviors (unpublished doctoral dissertation), University of Phoenix.

*Bond, F. W., \& Donaldson-Feilder, E. J. (2004). The relative importance of psychological acceptance and emotional intelligence to workplace well-being. British Journal of Guidance \& Counselling, 32, 187-203.

Boyatzis, R., Brizz, T., \& Godwin, L. (2011). The effect of religious leaders' emotional and social competencies on improving parish vibrancy. Journal of Leadership \& Organizational Studies, 18, 192-206.

Boyatzis, R. E., \& Goleman, D. (2002). The emotional competency inventory. Boston, MA: The Hay Group.

*Brackett, M. A., Palomera, R., Mojsa-Kaja, J., Reyes, M. R., \& Salovey, P. (2010). Emotionregulation ability, burnout, and job satisfaction among British secondary-school teachers. Psychology in the Schools, 47, 406-417.

Byron, K. (2007). Male and female managers' ability to read emotions: Relationships with supervisors' performance ratings and subordinates' satisfaction ratings. Journal of Occupational and Organizational Psychology, 80, 713-733.

Cherniss, C. (2001). Emotional intelligence and organizational effectiveness. In C. Cherniss \& D. Goleman (Eds.), The emotionally intelligent workplace (pp. 3-12). San Francisco: Jossey-Bass. 
Cohen, J. (1988). Statistical power analysis for the behavioral sciences (2nd ed.). Hillsdale, NJ: Erlbaum.

Colquitt, J. A., Scott, B. A., \& LePine, J. A. (2007). Trust, trustworthiness, and trust propensity: A meta-analytic test of their unique relationships with risk taking and job performance. Journal of Applied Psychology, 92, 909-927.

Crawford, E. R., LePine, J. A., \& Rich, B. L. (2010). Linking job demands and resources to employee engagement and burnout: A theoretical extension and meta-analytic test. Journal of Applied Psychology, 95, 834-848.

Demerouti, E., Bakker, A. B., Nachreiner, F., \& Schaufeli, W. B. (2001). The job demandsresources model of burnout. Journal of Applied Psychology, 86, 499-512.

Denton, D. W., \& Kleiman, L. S. (2001). Job tenure as a moderator of the relationship between autonomy and satisfaction. Applied HRM research, 6, 105-114.

El Badawy, T. A., \& Magdy, M. M. (2015). Assessing the impact of emotional intelligence on job satisfaction: An empirical study on faculty members with respect to gender and age. International Business Research, 8, 67-78.

Extremera, N., Fernández-Berrocal, P., \& Salovey, P. (2006). Spanish version of the MayerSalovey-Caruso Emotional Intelligence Test (MSCEIT). Version 2.0: reliabilities, age and gender differences. Psicothema, 18, 42-48.

Garrett, R. P., Miao, C., Qian, S., \& Bae, T. J. (2017). Entrepreneurial spawning and knowledgebased perspective: A meta-analysis. Small Business Economics. Online early view, doi: $10.1007 / \mathrm{s} 11187-017-9842-1$

Goleman, D. (1995). Emotional intelligence: Why it can matter more than IQ. New York, NY: Bantam Books. 
Goleman, D., Boyatzis, R., \& McKee, A. (2002). Primal leadership: Realizing the power of emotional intelligence. Cambridge, MA: Harvard Business School Press.

Halbesleben, J. R. B., Neveu, J.-P., Paustian-Underdahl, S. C., \& Westman, M. (2014). Getting to the "COR": Understanding the role of resources in conservation of resources theory. Journal of Management, 40, 1334-1364.

Hobfoll, S. E. (2001). The influence of culture, community, and the nested-self in the stress process: Advancing conservation of resources theory. Applied Psychology: An International Review, 50, 337-70.

*Ho, C. (2003). An empirical study of the relationship between emotional intelligence, perceptions of organizational politics, perceptions of organizational support, and organizational citizenship behavior. Unpublished doctoral dissertation, Webster University, Saint Louis, Missouri.

Humphrey, R. H. (2013). Effective Leadership: Theory, cases, and applications. Los Angeles, CA: Sage.

Humphrey, R. H., Ashforth, B. E., \& Diefendorff, J. M. (2015). The bright side of emotional labor. Journal of Organizational Behavior, 36, 749-769.

Hunter, J. E., \& Schmidt, F. L. (1990). Methods of meta-analysis: Correcting error and bias in research findings. Beverly Hills, CA: Sage.

Hunter, J. E., \& Schmidt, F. L. (2004). Methods of meta-analysis: Correcting error and bias in research findings. Newbury Park, CA: Sage.

*Jain, A. K., \& Sinha, A. K. (2005). General health in organizations: Relative relevance of emotional intelligence, trust, and organizational support. International Journal of Stress Management, 12, 257-273. 
*Johnson, H. A. M., \& Spector, P. E. (2007). Service with a smile: Do emotional intelligence, gender, and autonomy moderate the emotional labor process? Journal of Occupational Health Psychology, 12, 319-333.

Jordan, P. J., Ashkanasy, N. M., Härtel, C. E., \& Hooper, G. S. (2002). Workgroup emotional intelligence: Scale development and relationship to team process effectiveness and goal focus. Human Resource Management Review, 12, 195-214.

Joseph, D. L., Jin, J., Newman, D. A., \& O'Boyle, E. H. (2015). Why does self-reported emotional intelligence predict job performance? A meta-analytic investigation of mixed EI. Journal of Applied Psychology, 100, 298-342.

Judge, T. A., \& Kammeyer-Mueller, J. D. (2012). Job attitudes. Annual Review of Psychology, 63, 341-367.

Jung, H. S., \& Yoon, H. H. (2014). Moderating role of hotel employees' gender and job position on the relationship between emotional intelligence and emotional labor. International Journal of Hospitality Management, 43, 47-52.

Kafetsios, K., \& Zampetakis, L. A. (2008). Emotional intelligence and job satisfaction: Testing the mediatory role of positive and negative affect at work. Personality and Individual Differences, 44, 712-722.

Kammeyer-Mueller, J. D., Simon, L. S., \& Judge, T. A. (2016). A head start or a step behind? Understanding how dispositional and motivational resources influence emotional exhaustion. Journal of Management, 42, 561-581.

*Kim, J. H., Lee, Y. M., Joung, H. Y., Choo, H. S., Won, S. J., Kwon, S. Y., Bae, H. J., Ahn, H. K., Kim, E. M., \& Jang, H. J. (2013). Effects of emotional labor, emotional intelligence 
and social support on job stress in clinical nurses. Journal of Korean Academy of Fundamentals of Nursing, 20, 157-167.

*Kleidon, M. W. (2010). The role of fatigue, safety climate, and emotional intelligence in shaping safety behaviours in aviation maintenance. Unpublished doctoral dissertation, University of Southern Queensland.

Koveshnikov, A., Wechtler, H., \& Dejoux, C. (2014). Cross-cultural adjustment of expatriates: The role of emotional intelligence and gender. Journal of World Business, 49, 362-371.

Kraemer, T., \& HJ Gouthier, M. (2014). How organizational pride and emotional exhaustion explain turnover intentions in call centers: A multi-group analysis with gender and organizational tenure. Journal of Service Management, 25, 125-148.

*Lekavičien, R., \& Remeikait, I. (2004). The relationship between employees’ emotional intelligence and socio-psychological climate in information technology organizations. Social Sciences, 45, 95-102.

Lipsey, M. W., \& Wilson, D. B. (2001). Practical meta-analysis. Sage Publications: Thousand Oaks, CA, 2001.

Lopes, P. N., Brackett, M. A., Nezlek, J. B., Schütz, A., Sellin, I., \& Salovey, P. (2004). Emotional intelligence and social interaction. Personality and Social Psychology Bulletin, 30, 1018-1034.

Martins, A., Ramalho, N., \& Morin, E. (2010). A comprehensive meta-analysis of the relationship between emotional intelligence and health. Personality and Individual Differences, 49, 554-564.

Mayer, J. D., Caruso, D. R., \& Salovey, P. (1999). Emotional intelligence meets traditional standards for an intelligence. Intelligence, 27, 267-298. 
Mayer, J. D., \& Salovey, P. (1997). What is emotional intelligence? In P. Salovey \& D. J. Sluyter (Eds.), Emotional development and emotional intelligence: Educational implications (pp. 3-25). New York: Basic Books.

Mayer, J. D., Salovey, P., Caruso, D., \& Sitarenios, G. (2003). Measuring emotional intelligence with the MSCEIT V2.0. Emotion, 3, 97-105.

Miao, C., Humphrey, R. H., \& Qian, S. (2016a). Leader emotional intelligence and subordinate job satisfaction: A meta-analysis of main, mediator, and moderator effects. Personality and Individual Differences, 102, 13-24.

Miao, C., Humphrey, R. H., \& Qian, S. (2016b). A meta-analysis of emotional intelligence and work attitudes. Journal of Occupational and Organizational Psychology. Online early view, doi:10.1111/joop.12167

Miao, C., Qian, S., \& Ma, D. (2017). The relationship between entrepreneurial self-efficacy and firm performance: A meta-analysis of main and moderator effects. Journal of Small Business Management, 55, 87-107.

Nahrgang, J. D., Morgeson, F. P., \& Hofmann, D. A. (2011). Safety at work: a meta-analytic investigation of the link between job demands, job resources, burnout, engagement, and safety outcomes. Journal of Applied Psychology, 96, 71-94.

O’Boyle, E. H., Humphrey, R. H., Pollack, J. M., Hawver, T. H., \& Story, P. A. (2011). The relation between emotional intelligence and job performance: A meta-analysis. Journal of Organizational Behavior, 32, 788-818.

Peterson, R. A., \& Brown, S. P. (2005). On the use of beta coefficients in meta-analysis. Journal of Applied Psychology, 90, 175-181. 
Petrides, K. V. (2009a). Psychometric properties of the Trait Emotional Intelligence Questionnaire (TEIQue). In C. Stough, D. H. Saklofske, \& J. D. A. Parker (Eds.), Assessing emotional intelligence: Theory, research, and applications (pp. 85-101). New York, NY: Springer Science.

Petrides, K. V. (2009b). Technical manual for the Trait Emotional Intelligence Questionnaire (TEIQue). London, England: London Psychometric Laboratory.

Petrides, K. V., Frederickson, N., \& Furnham, A. (2004). The role of trait emotional intelligence in academic performance and deviant behavior at school. Personality and Individual Differences, 36, 277-293.

Petrides, K. V., \& Furnham, A. (2000). On the dimensional structure of emotional intelligence. Personality and Individual Differences, 29, 313-320.

Petrides, K. V., \& Furnham, A. (2001). Trait emotional intelligence: Psychometric investigation with reference to established trait taxonomies. European Journal of Personality, 15, 425448.

Petrides, K. V., \& Furnham, A. (2003). Trait emotional intelligence: Behavioural validation in two studies of emotion recognition and reactivity to mood induction. European Journal of Personality, 17, 39-57.

Petrides, K. V., \& Furnham, A. (2006). The role of trait emotional intelligence in a gender-specific model of organizational variables. Journal of Applied Social Psychology, $36,552-569$.

Petrides, K. V., Mikolajczak, M., Mavroveli, S., Sanchez-Ruiz, M. J., Furnham, A., \& PérezGonzález, J. C. (2016). Developments in trait emotional intelligence research. Emotion Review, 8, 335-341. 
Petrides, K. V., Pita, R., \& Kokkinaki, F. (2007). The location of trait emotional intelligence in personality factor space. British Journal of Psychology, 98, 273-289.

*Rey, L., \& Extremera, N. (2011). Social support as mediator of perceived emotional intelligence and life satisfaction in a sample of teachers. Revista de Psicología Social, 26, 401-412.

Roth, P. L., Le, H., Oh, I.-S., Van Iddekinge, C., \& Robbins, S. B. (in press). Who r u?: On the (in)accuracy of incumbent-based estimates of range restriction in criterion-related and differential validity research. Journal of Applied Psychology.

*Saad, K. (2011). Emotionally smart makes you more motivated: Associations between emotional intelligence, motivation, and work outcomes in police source handlers. Unpublished doctoral dissertation, University of Ottawa.

*Salami, S. O. (2010). Occupational stress and well-being: Emotional intelligence, self-efficacy, coping, negative affectivity and social support as moderators. The Journal of International Social Research, 3, 387-398.

Salguero, J. M., Extremera, N., \& Fernández-Berrocal, P. (2012). Emotional intelligence and depression: The moderator role of gender. Personality and Individual Differences, 53, 2932.

Salovey, P., \& Mayer, J. D. (1990). Emotional intelligence. Imagination, Cognition and Personality, 9, 185-211.

Schutte, N. S., Malouff, J. M., Bobik, C., Coston, T. D., Greeson, C., \& Jedlicka, C. (2001). Emotional intelligence and interpersonal relations. The Journal of Social Psychology, $141,523-536$. 
Schutte, N. S., Malouff, J. M., Thorsteinsson, E. B., Bhullar, N., \& Rooke, S. E. (2007). A metaanalytic investigation of the relationship between emotional intelligence and health. Personality and Individual Differences, 42, 921-933.

Schwab, D. P. (2005). Research methods for organizational studies. Psychology Press.

Stahl, G. K., \& Caligiuri, P. (2005). The effectiveness of expatriate coping strategies: the moderating role of cultural distance, position level, and time on the international assignment. Journal of Applied Psychology, 90, 603-615.

Taylor, S. N., \& Hood, J. N. (2011). It may not be what you think: Gender differences in predicting emotional and social competence. Human Relations, 64, 627-652.

*Tan, S. (2006). The influences of employees' emotional intelligence on organizational climate and job satisfaction. Unpublished master's thesis, Soochow University.

van der Linden, D., Pekaar, K. A., Bakker, A. B., Schermer, J. A., Vernon, P. A., Dunkel, C. S., \& Petrides, K. V. (2017). Overlap between the general factor of personality and emotional intelligence: A meta-analysis. Psychological Bulletin, 143, 36-52.

Viswesvaran, C., \& Ones, D. S. (1995). Theory testing: Combining psychometric meta-analysis and structural equations modeling. Personnel Psychology, 48, 865-885.

Walter, F., Cole, M. S., \& Humphrey, R. H. (2011). Emotional intelligence: Sine qua non of leadership or folderol? The Academy of Management Perspectives, 25, 45-59.

Walter, F., Humphrey, R. H., \& Cole, M. S. (2012). Unleashing leadership potential: Toward an evidence-based management of emotional intelligence. Organizational Dynamics, 41, 212-219.

Wong, C.-S., \& Law, K. S. (2002). The effects of leader and follower emotional intelligence on performance and attitude: An exploratory study. The Leadership Quarterly, 13, 243-274. 
*Yuan, S. J., \& Hu, Y. X. (2008). Empirical study on the relationship between the emotional intelligence of grass-roots civil servants and social support. Journal of China Executive Leadership Academy Pudong, 2, 58-64.

*Zampetakis, L. A., Beldekos, P., \& Moustakis, V. S. (2009). “Day-to-day” entrepreneurship within organisations: The role of trait emotional intelligence and perceived organisational support. European Management Journal, 27, 165-175. 
Table 1. Psychometric Meta-Analysis Results

\begin{tabular}{|c|c|c|c|c|c|c|c|c|c|c|}
\hline & $k$ & $N$ & $\bar{r}_{o}$ & $S D_{r}$ & $\hat{\rho}$ & $S D_{\rho}$ & $\operatorname{Var}_{\text {art }} \%$ & $\begin{array}{l}\text { Corrected } \\
95 \% \mathrm{CI}\end{array}$ & $\begin{array}{l}\text { Corrected } \\
80 \% \mathrm{CR}\end{array}$ & $\begin{array}{l}\text { Significant } \\
\text { Difference }\end{array}$ \\
\hline EI-Job Resources & 15 & 4,151 & .23 & .08 & .27 & .05 & 68 & .24 to .31 & .21 to .33 & \\
\hline Ability EI-Job Resources & 1 & 123 & .21 & .00 & .24 & .00 & NA & .24 to .24 & .24 to .24 & \\
\hline Self-report EI-Job Resources & 11 & 3,087 & .23 & .08 & .27 & .06 & 52 & .23 to .32 & .19 to .35 & \\
\hline Mixed EI — Job Resources & 3 & 941 & .23 & .04 & .28 & .00 & 100 & .26 to .30 & .28 to .28 & \\
\hline \multicolumn{11}{|l|}{$\begin{array}{c}\text { Ability EI-Job Satisfaction } \\
\text { Gender }\end{array}$} \\
\hline a. Male Dominated & 6 & 1056 & .06 & .12 & .07 & .11 & 41 & -.04 to .19 & -.07 to .21 & - \\
\hline $\begin{array}{l}\text { b. Female Dominated } \\
\text { Age }\end{array}$ & 6 & 815 & .05 & .09 & .06 & .04 & 87 & -.01 to .14 & .01 to .11 & - \\
\hline a. Young (before age of 40 ) & 9 & 1587 & .06 & .09 & .07 & .06 & 70 & .01 to .14 & -.00 to .15 & - \\
\hline $\begin{array}{l}\text { b. Middle- or old-age (after age of 40) } \\
\text { Job Level }\end{array}$ & 2 & 166 & .21 & .21 & .24 & .20 & 26 & -.03 to .50 & -.02 to .50 & - \\
\hline a. Managerial & 3 & 234 & .09 & .15 & .11 & .11 & 58 & -.06 to .27 & -.03 to .25 & - \\
\hline b. Non-Managerial & 9 & 1453 & .06 & .12 & .07 & .10 & 43 & -.01 to .16 & -.06 to .21 & - \\
\hline \multicolumn{11}{|l|}{$\begin{array}{c}\text { Self-Report EI-Job Satisfaction } \\
\text { Gender }\end{array}$} \\
\hline a. Male Dominated & 28 & 7,270 & .29 & .14 & .34 & .15 & 18 & .29 to .40 & .16 to .53 & - \\
\hline $\begin{array}{l}\text { b. Female Dominated } \\
\text { Age }\end{array}$ & 28 & 10,811 & .28 & .09 & .32 & .09 & 29 & .28 to .35 & .21 to .43 & - \\
\hline a. Young (before age of 40 ) & 30 & 7,344 & .26 & .14 & .31 & .15 & 18 & .25 to .37 & .12 to .50 & - \\
\hline \multicolumn{10}{|l|}{ Tenure } & - \\
\hline a. Short & 9 & 2,237 & .26 & .07 & .30 & .00 & 100 & .27 to .32 & .30 to .30 & - \\
\hline b. Long & 9 & 2,120 & .25 & .11 & .30 & .12 & 30 & .25 to .35 & .15 to .45 & - \\
\hline Job Level & & & & & & & & & & \\
\hline a. Managerial & 7 & 1,994 & .23 & .05 & .27 & .00 & 100 & .25 to .29 & .27 to .27 & $\mathrm{~b}$ \\
\hline b. Non-Managerial & 41 & 13,929 & .28 & .11 & .33 & .11 & 21 & .29 to .37 & .19 to .48 & $\mathrm{a}$ \\
\hline \multicolumn{11}{|l|}{$\begin{array}{c}\text { Mixed EI-Job Satisfaction } \\
\text { Gender }\end{array}$} \\
\hline a. Male Dominated & 16 & 3,401 & .31 & .12 & .37 & .13 & 25 & .32 to .41 & .20 to .53 & - \\
\hline $\begin{array}{l}\text { b. Female Dominated } \\
\text { Age }\end{array}$ & 16 & 2,124 & .28 & .29 & .33 & .34 & 8 & .23 to .44 & -.10 to .76 & - \\
\hline
\end{tabular}




\begin{tabular}{rllllllllll} 
a. Young (before age of 40) & 10 & 1,963 & .24 & .20 & .28 & .22 & 11 & .21 to .36 & -.00 to .57 & - \\
\hline e- or old-age (after age of 40) & 5 & 479 & .20 & .18 & .23 & .17 & 32 & .17 to .30 & .02 to .45 & -
\end{tabular}

b. Middle- or old-age (after age of 40) 5479

Job Level

$\begin{array}{rllllllllll}\text { a. Managerial } & 7 & 1,230 & .40 & .32 & .47 & .38 & 4 & .35 \text { to } .59 & -.02 \text { to } .96 & - \\ \text { Non-Managerial } & 21 & 4,276 & .31 & .12 & .37 & .13 & 26 & .32 \text { to } .41 & .20 \text { to } .53 & -\end{array}$

Note. $k=$ number of independent samples; $N=$ sample size; $\bar{r}_{o}=$ uncorrected sample-size-weighted mean correlation; $S D_{r}=$ sample-size-weighted standard deviation of observed mean correlations; $\hat{\rho}=$ corrected sample-size-weighted mean correlation; $S D_{\rho}=$ sample-size-weighted standard deviation of corrected mean correlations; $\mathrm{Var}_{\mathrm{art}} \%=$ percent of variance in $\hat{\rho}$ explained by statistical artifacts; Corrected $95 \% \mathrm{CI}=$ corrected $95 \%$ confidence interval; Corrected $80 \%$ $\mathrm{CR}=$ corrected $80 \%$ credibility interval; Significant Difference $=$ letters in this column corresponds to the letters in rows and suggest that effect sizes are significantly different from one another at .05 level. The sign "- " indicates there is no significant between-group difference. EI = emotional intelligence. 
Table 2. Comparison of the Fit of the Alternative Models

Test 1: Job resource as a mediator between ability EI and self-report EI and job satisfaction (Harmonic Mean = 634)

\begin{tabular}{llllllllll} 
& \multicolumn{1}{c}{$\chi^{2}$} & $d f$ & $p$ value of $\chi^{2}$ & CFI & NFI & GFI & RMR & RMSEA & ${ }^{\mathrm{a}} \Delta \chi^{2}(\Delta d f)$ \\
\hline Model 1: Partial Mediation (a) & $\mathbf{0 . 0 0}$ & $\mathbf{0}$ & - & $\mathbf{1 . 0 0}$ & $\mathbf{1 . 0 0}$ & $\mathbf{1 . 0 0}$ & $\mathbf{. 0 0}$ & - & \\
Model 2: Partial Mediation (b) & 28.15 & 1 & .00 & .94 & .93 & .98 & .05 & .21 & $28.15^{* * * *}(1)$ \\
Model 3: Partial Mediation (c) & 6.96 & 1 & .01 & .99 & .98 & .99 & .02 & .10 & $6.96^{* * *}(1)$ \\
Model 4: Full Mediation & 33.33 & 2 & .00 & .93 & .92 & .98 & .05 & .16 & $33.33^{* * *}(2)$ \\
Model 5: No Mediation & 78.50 & 2 & .00 & .82 & .82 & .94 & .13 & .25 & $78.50^{* * *}(2)$ \\
\hline
\end{tabular}

Test 2: Job resource as a mediator between mixed EI and job satisfaction (Harmonic Mean = 2,447)

\begin{tabular}{|c|c|c|c|c|c|c|c|c|c|}
\hline & $\chi^{2}$ & $d f$ & $p$ value of $\chi^{2}$ & CFI & NFI & GFI & RMR & RMSEA & ${ }^{\mathrm{a}} \Delta \chi^{2}(\Delta d f)$ \\
\hline Model 1: Partial Mediation & 0.00 & $\mathbf{0}$ & - & 1.00 & 1.00 & 1.00 & .00 & - & \\
\hline Model 2: Full Mediation & 210.72 & 1 & .00 & .87 & .87 & .95 & .09 & .29 & $210.72^{* * *}(1)$ \\
\hline Model 3: No Mediation & 199.70 & 1 & .00 & .88 & .87 & .95 & .14 & .29 & $199.70^{* * *}(1)$ \\
\hline
\end{tabular}

Note. $d f=$ degree of freedom; CFI = comparative fit index; NFI = normed fit index; GFI = goodness of fit index; RMR = root mean square residual; RMSEA = root mean square error of approximation; EI = emotional intelligence. $\chi^{2}$ difference tests were performed based on the comparison with Model 1 . Partial mediation (a) contains direct paths from both ability EI and self-report EI to job satisfaction. Partial mediation (b) contains a direct path from only ability EI to job satisfaction. Partial mediation (c) contains a direct path from only self-report EI to job satisfaction. The models with bold characters refer to the chosen ones according to the results of model comparison.

${ }^{* *} p<.01$

**** $p<.001$ 
Figure 1. Path Models of the Mediating Role of Job Resource in the Relationship between EI and Job Satisfaction

a)

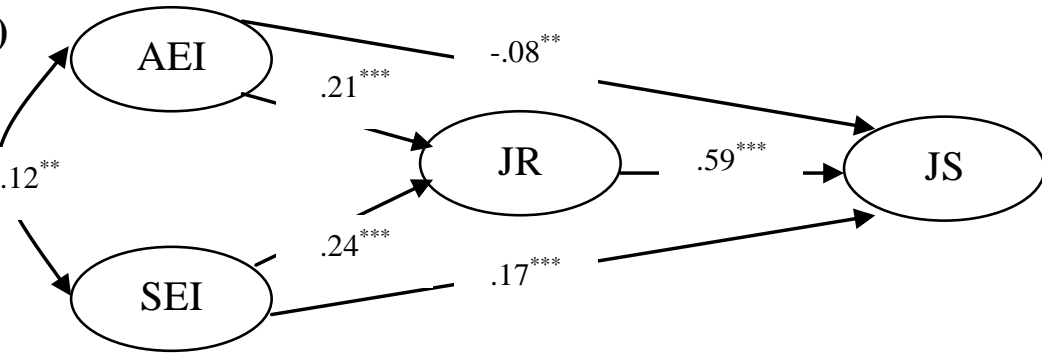

AEI: Mediation effect of JR $\rightarrow .211[.038] \times .594[.032]=.13^{* * *}$

AEI: Sobel test: 5.32; Aroian test $=5.31$; Goodman test $=5.33$

SEI: Mediation effect of JR $\rightarrow .245[.038] \times .594[.032]=.15^{* * *}$

SEI: Sobel test: 6.09 ; Aroian test $=6.08$; Goodman test $=6.10$ b)

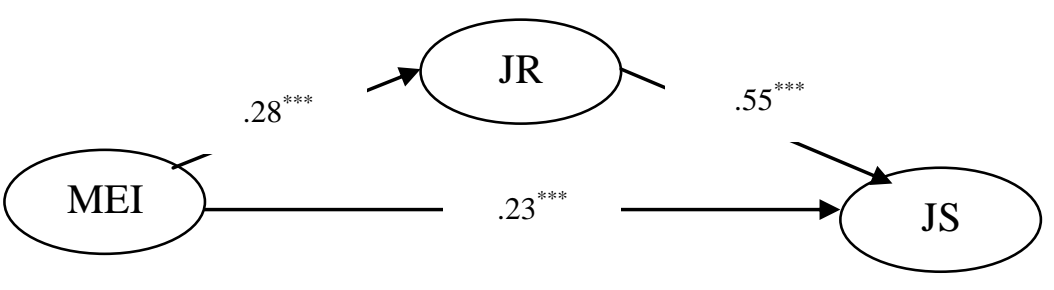

Mediation effect of JR $\rightarrow .280[.019] \times .554[.016]=.16^{* * *}$

Sobel test: 13.56 ; Aroian test $=13.55$; Goodman test $=13.56$

Note. Standardized path coefficients are reported. Standard errors are reported in brackets. AEI $=$ ability emotional intelligence; SEI $=$ self-report emotional intelligence; $\mathrm{MEI}=$ mixed emotional intelligence; JS = job satisfaction; JR = job resource. Figure 1 (a) corresponds to Model 1 under Test 1 in Table 2, and Figure 1 (b) corresponds to Model 1 under Test 2 in Table 2.

${ }^{* *} p<.01$

${ }^{* * * *} p<.001$ 